\section{Graduate Programs: Preparing Students for the Future or for the Past?}

What do graduate programs look like in the mathematical sciences? Typically students take courses to prepare for qualifying exams, followed by courses to prepare for research. These activities lead to a thesis. Seminars and colloquium speakers are focused on research topics. Students are supported as research assistants or teaching assistants. The latter position might come with training for teaching. This structure points to one goal: Creating researchers and creating publishable mathematics.

An indication that this goal is not being achieved comes from [1]. Grossman looked at Math Reviews from 1940 to 1999 . This data represents publications from 300,000 authors and included 1.6 million articles. Grossman found that 43 percent of authors had exactly one paper in Math Reviews and 75 percent had no more than five papers!

The research experience is invaluable. The in-depth study of mathematical ideas provides for profound understanding. Defining a research problem, developing a program of attack, writing up the solution, and giving presentations are important experiences that prove useful both for the classroom as well as for employment outside academia, as the following data show.

In 2009 the percentage of employment of new doctorates in US nonacademic positions was 23 percent, rising to 29 percent in 2013 [2]. This employment picture shows the broad utility of mathematical training. Mathematicians are in demand. If graduate programs paid more attention to these nonacademic positions, we could greatly expand the opportunities for all our graduates. Linkages between mathematics departments and industry should be increased, and summer employment at national laboratories and industry for faculty and graduate students would provide a better understanding of how mathematics is employed in the workforce. These experiences would then inform the curriculum.

Despite the increase in the number of mathematics doctorates taking jobs outside academia, most of them still make their living by teaching. And yet, with some outstanding exceptions, graduate programs in mathematics largely ignore this aspect of the profession. Once we begin teaching we have to understand how to deal with students who arrive unprepared for collegiate mathematics. Should we continue to lecture, or is there something to be learned from advances in learning theories, innovative teaching styles, and the effective use of technology? At many universities, mathematicians play a role in the training of K-12 teachers, an activity which has many challenges.

DOI: http://dx.doi.org/10.1090/noti1259
The current situation is that on-the-job training for these many responsibilities is the rule. The education graduate students obtain does not adequately prepare them for the many tasks a faculty member must address.

It is time to look at graduate programs more carefully. I suggest that all programs in the mathematical sciences perform a series of self-studies.

Employment Self-Study: Where are your graduates being employed? Though this information is difficult to obtain for bachelor's students, it is much easier to obtain for master's and PhD students. In particular, where the doctoral graduates end up after 5-10 years is important. If the graduates are going mostly to nonresearch-intensive colleges, then the graduate education should reflect this reality.

Funding agencies recognize the importance of creating a diverse scientific workforce. Given the changing demographics, it is increasingly important that underserved populations be part of this workforce, and success in mathematics is essential. Mathematics departments should take a leadership role in addressing the needs of the US workforce, and they should take seriously the responsibility of producing a mathematically literate student body. We should use the mathematics classes that we teach as a vehicle for encouraging students to take the next mathematics class and to consider adding the mathematics major to their program of study [3]. Departments that request funding from these agencies should join in the efforts to produce a diverse, mathematically literate workforce.

Demographic Self-Study: How well is the department educating the US population? A self-study should include how many mathematics majors and minors there are at the undergraduate level, broken down by US citizen-international, male-female, and underrepresented minorities. This same data should also be provided for graduate programs.

These self-studies should be part of individual research proposals to funding agencies, and the evaluation of individual proposals should be impacted by the self-studies of the department. If a department cannot provide evidence that it is producing a diverse workforce, then grants should go to other departments that more clearly support the goals of the funding agencies.

\section{References}

1. Jerrold W. Grossman, Patterns of research in mathematics, Notices of the AMS 52 no. 1, (2005), 35-41.

2. William Yslas Vélez, James W. Maxwell, Colleen Rose, Report on the 2012-2013 new doctoral recipients, Notices of the AMS 61 (2014), no. 8, 874-884.

3. WiLliam YsLAS VÉLEZ, Mathematics instruction, an enthusiastic activity, On Teaching and Learning Mathematics, AMS Blogs, August 1, 2014.

-William Yslas Vélez University of Arizona velez@math. arizona.edu 